\title{
Sobre a perda parcial do movimento do verbo no português brasileiro: a analiticização do tempo futuro ${ }^{i}$
}

Resumo: Argumento que, contrariamente à Biberauer \& Roberts (2010), o verbo (ainda) se move (parcialmente) no PB. Proponho que o processo de analiticização de futuridade desencadeou perda de movimento a uma posição mais alta (TP), muito embora o verbo continue se movendo para um núcleo mais baixo (WollP). A ausência de temporalidade do futuro sintético no PB falado, a ordem do advérbio 'sempre' e o licenciamento da elipse de VP sugerem que o pouso do verbo foi alterado. A leitura temporal de futuridade, agora, é derivada por um traço (de modo) irrealis, e não mais temporal, como era até o século XIX.

Palavras-chave: Analiticização. Tempo futuro. Movimento do verbo. Português brasileiro.

\begin{abstract}
I argue that, contrary to Biberauer \& Roberts's (2010) analysis, verb (still) moves (partially) in BP. I show that an analyticization process of futurity entailed loss of verb movement to a higher head (TP), but the verb still moves to a lower one, namely (WollP). The lack of temporal meaning of synthetic future in spoken BP, the licensing of VP ellipsis and the order of 'sempre' adverb suggest that some landing movement has been altered. Futurity temporal meaning, now, is derived from irrealis (mood) features, not from a temporal one, as it was until the XIX century. Keywords: Analyticization. Future tense. Verb movement. Brazilian Portuguese.
\end{abstract}

Resumen: Sostengo que, diferente de Biberauer \& Roberts (2010), el verbo (todavía) se mueve (parcial) en PB. Muestro que el proceso de analiticización de futuridad conllevó pérdida de movimiento verbal a una cabeza más alta (TP), pero el verbo todavía se mueve a un núcleo más bajo (WollP). La falta de significado temporal del futuro sintético en lo PB hablado, la licencia de elipsis de VP y el orden del adverbio 'sempre' sugieren que se ha modificado algún movimiento de aterrizaje. El significado temporal de futuridad, ahora, deriva de rasgos irrealis (modo), no de uno temporal, como fue hasta el siglo XIX.

Palabras clave: Analiticización. Tiempo Futuro. Movimiento del Verbo. Portugués Brasileño.

\footnotetext{
${ }^{\mathrm{i}}$ Este texto foi escrito com o financiamento da CAPES (código de financiamento oo1), durante o mestrado. Agradeço à leitura cuidadosa de Sonia Cyrino na primeira versão deste texto. Agradeço também aos dois pareceristas anônimos pelas observações e sugestões ao trabalho. Ainda que nem todas puderam ser contempladas neste artigo, elas serão levadas em consideração em trabalhos futuros.

* Doutorando em Linguística pelo Programa de Pós-Graduação em Linguística da UNICAMP, na área de sintaxe diacrônica sob uma perspectiva da Gramática Gerativa. http://orcid.org/0000-0002-9884-0723
}

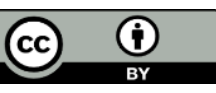




\section{Introdução}

Dentre muitos trabalhos (cf. DEGRAFF, 1997; VIKNER, 1997) que se dedicaram a explicar o movimento do verbo nas línguas, Biberauer \& Roberts (2010) propõem uma direta relação entre a riqueza da flexão temporal e o movimento de verbo (para T). De acordo com os autores, baseados em Koeneman \& Neeleman (2001), há uma certa tipologia no que concerne à riqueza da concordância e à riqueza da flexão temporal com o movimento do verbo a T e sujeito nulo. Essa tipologia está apresentada a seguir:

(1) a. Concordância rica e flexão temporal rica: com movimento v para $\mathrm{T}$ e sujeito nulo, e.g. italiano, grego, espanhol, etc.

b. Concordância pobre mas flexão temporal rica: com movimento v para T, mas sem sujeito nulo, e.g. francês.

c. Concordância pobre e flexão temporal pobre: sem movimento v para T e sem sujeito nulo, e.g. inglês moderno.

d. Concordância rica e flexão temporal pobre: sem movimento v para $\mathrm{T}$ e com sujeito nulo, e.g., sem exemplo atestado.

Biberauer \& Roberts (2010) argumentam que a principal correlação entre o movimento do verbo e a riqueza da flexão é que a última está relacionada a traços fortes e, devido a isso, ao movimento verbal visível, dentro de uma abordagem chomskyana. Para eliminar o traço EPP que desencadeia movimento, como é na proposta de Chomsky (1995), os autores propõem que Tempos ricos não são simples Vs, mas, ao invés disso, são elementos compostos de V e um T totalmente especificado.

Entretanto, em relação ao português brasileiro (PB), é amplamente aceito que essa língua não apresenta morfologia de concordância forte (cf. DUARTE, 1995; GALVES, 2001, 1993). Além disso, em relação à flexão temporal, o PB parece estar em processo de analiticização, i.e., o processo pela preferência por formas perifrásticas a sintéticas. Reintges \& Cyrino (2018), por exemplo, argumentam que esse processo está em um estágio avançado no português brasileiro:

\section{Quadro 1 - Paradigma da flexão temporal no PB}




\begin{tabular}{|c|c|c|}
\hline Presente & TEMPO SINTÉTICO & TEMPO PERIFRÁSTICO \\
\hline Imperfeito & eu almoço & $\begin{array}{c}\text { Eu estou falando } \\
\text { Eu tenho almoçado }\end{array}$ \\
\hline Futuro & eu almoçarei & Eu estava almoçando \\
\hline Mais-que-perfeito & eu almoçara & Eu vou almoçar \\
\hline Passado simples & eu almocei & - \\
\hline Futuro perfeito & - & $\begin{array}{c}\text { Eu vou ter almoçado/Eu terei } \\
\text { almoçado }\end{array}$ \\
\hline Passado perfeito & - & *Eu tive almoçado \\
\hline
\end{tabular}

Fonte: adaptado de REINTGES \& CYRINO (2018)

Somando-se à ideia de que o PB tem uma morfologia de concordância fraca e um paradigma temporal também fraco, essa língua deveria ser considerada uma língua do tipo exposto em (1c), isto é, de acordo com Biberauer \& Roberts (2010), o português brasileiro não deveria ter sujeito nulo (o que parece ir ao encontro das pesquisas sobre o tema, como em KATO \& NEGRÃO, 20oo), nem movimento de v para T. Relacionado ao último, Cyrino (2013), quando analisa o Tempo passado do PB, mostra que essa não parece ser toda a história. Assim, seguindo Cyrino (2013), este artigo mostra que o PB perdeu movimento verbal, mas não todo o movimento verbal no sentido radical de Biberauer \& Roberts (2010) - é possível verificar um movimento parcial do verbo que dispara uma leitura de futuridade. Como vamos advogar, para veicular futuridade a forma sintética de futuro no PB era licenciada pelo movimento de $\mathrm{v}$ para $\mathrm{T}$, porém, com o processo de analiticização se intensificando, a estrutura perifrástica se tornou amplamente usada pelos falantes. As únicas formas sintéticas no PB contemporâneo falado são destituídas de interpretação temporal (conforme será mostrado em § 4); como consequência, o verbo começou a ter como alvo para o movimento uma categoria abaixo de TP; o movimento do verbo se reduziu para checar somente traços IRREALIS: a leitura de futuridade, veiculada pela perífrase, é derivada por traços de modo.

'Pode-se dizer que (i) "eu almoçava naquele restaurante todo dia" e (ii) "eu estava almoçando naquele restaurante todo dia" não teriam a mesma leitura: no primeiro haveria uma leitura habitual e no segundo não. Porém, em uma sentença como "Eu almoçava/estava almoçando no restaurante quando a energia acabou", uma leitura progressiva é obtida; ou seja, nesse contexto parecem ser intercambiáveis. De qualquer modo, entende-se a importância de um olhar mais atento para essas estruturas, bem como suas diferentes nuances semânticas. 
O artigo está organizado da maneira como se segue: em $\S 1$ discutimos a proposta de Biberauer \& Roberts (2010), relacionando-a ao paradigma temporal do PB. Em $§ 2$, apresentamos alguns dados históricos sobre o Tempo futuro no PB, além do conhecimento linguístico dos falantes de $\mathrm{PB}$ em relação ao Tempo futuro. Em $\S 3$ apresentamos nossa proposta sintática para os dados, e em $\S 4$ apresentamos algumas evidências para nossa proposta, mostrando que o movimento do verbo nas estruturas de futuridade ainda ocorre (mas para uma projeção mais baixa que TP). Finalmente, a última seção faz algumas considerações finais e, brevemente, aponta questões para pesquisas futuras.

\section{Proposta de Biberauer \& Roberts (2010)}

A generalização de que o movimento do verbo está relacionado com sujeito nulo, como já mencionado, em que o verbo se move para T, ou para I na nomenclatura mais antiga, para licenciar sujeito nulo, é problemática devido ao fato de que o francês não apresenta sujeito nulo, muito embora o movimento do verbo até T seja visível, como mostram Biberauer \& Roberts (2010) (cf. (2)). A observação de que o francês não tem marcação rica de concordância também elimina a hipótese de que há uma relação estreita entre movimento de v para T e sujeito nulo (cf. (3)). Em (2), a seguir, o verbo se encontra à esquerda do advérbio souvent, pois, assumindo que advérbios são fixos na estrutura (POLLOCK, 1989), embrasse se moveu (esse movimento é representado pelo vestígio $t$ ) da sua posição temática para uma posição acima do advérbio, no caso, TP. Caso o sujeito nulo fosse licenciado pelo movimento do verbo a $\mathrm{T}$, esperaríamos que o francês permitisse sujeitos nulos, o que não é verdade, como (3) mostra: a opcionalidade do expletivo torna a sentença agramatical.

(2) Jean embrasse en $_{i}$ souvent $t_{i}$ Marie Jean beija frequentemente Marie 'Jean beija frequentemente a Maria'

$\begin{array}{lllll}\text { (3) (Il) ya } & \text { une licorne } & \text { dansle } & \text { jardin } \\ \text { Há } & \text { um unicórnio no } & \text { jardim }\end{array}$

'Há um unicórnio no jardim' 
Biberauer \& Roberts propuseram uma alternativa relacionando a projeção T e a flexão temporal como uma configuração paramétrica (eles omitem referência a v). De acordo com os autores, V e T entram em uma relação de AGREE, de modo a satisfazer seus traços: T tem um traço-V não valorado (uma vez que T é inerentemente verbal), embora careça de propriedade semântica do verbo, a saber, estrutura argumental².

Uma vez que verbos finitos podem carregar morfologia temporal, mas não conteúdo temporal por si, V tem um traço-temporal não valorado. Dessa maneira, seguindo Chomsky (2000, 2001), Biberauer \& Roberts (2010) propõem que T age como uma sonda e V como um alvo. Esses traços são valorados da seguinte maneira: em inglês, é necessário que seja inserido um auxiliar Affix Hopping. Em alemão, V só se move em um contexto V2, portanto somente para $C$, nunca para T. Assim, T e V estabelecem uma relação de concordância sem movimento-v (em contextos não V2). Nas línguas românicas, deve haver um traço EPP em T que desencadeia o movimento do verbo.

Desse modo, os autores argumentam que a diferença entre as línguas germânicas e as românicas é a riqueza da marcação da flexão (sintética) nos diferentes Tempos. Por exemplo, Biberauer \& Roberts (2010, p. 19) afirmam que o francês tem entre quatro e seis 3 Tempos sintéticos e seria, pois, uma língua temporalmente rica, e o inglês, que tem somente duas, seria temporalmente pobre. Nessa perspectiva, as línguas românicas seriam mais ricas que as germânicas:

\section{(4) Línguas Românicas}

Francês: parle (presente indicativo/subjuntivo), parlerai (futuro), parlerais (condicional), parlais (imperfeito), parlai (pretérito), parlasse (pretérito subjuntivo).

Italiano: parlo (presente), parlerò (futuro), parlerei (condicional), parlavo (imperfeito), parli (presente subjuntivo), parlassi (passado subjuntivo), parlai (pretérito).

Espanhol: hablo (presente), hablarò (futuro), hablaria (condicional), hablaba

\footnotetext{
${ }^{2}$ Essa mesma restrição proposta por Biberauer \& Roberts (2010) pode ser analisada em termos de c-seleção e s-seleção: $T$, sendo um núcleo funcional, só tem propriedades de c-seleção; no caso sua restrição categorical seria $\mathrm{V}$.

${ }^{3}$ Os autores fazem essa aproximação (entre quatro e seis), pois entendem que as duas últimas formas verbais no francês (parlais e parlasse) são usadas somente na linguagem literária e no contexto escolar.
} 
(imperfeito), hablé (pretérito), hable (presente subjuntivo), hablase (passado subjuntivo I), hablara (passado subjuntivo II).

(5) Línguas Germânicas

Alemão: sprech (presente), sprach (passado), sprache (passado subjuntivo).

Inglês: speak (presente), spoke (passado).

Suéco: snakker (presente), snakket (passado).

Biberauer \& Roberts (2010) sugerem que há duas instâncias de riqueza da flexão verbal: (i) flexão da concordância e (ii) flexão temporal. A primeira pode ser forte/rica ou fraca/pobre. A FLEXÃO DE CONCORDÂNCIA RICA desencadeia um movimento de uma categoria D (V em línguas de sujeito nulo). Por outro lado, a FLEXÃO DE CONCORDÂNCIA POBRE determina a presença de um expletivo visível. Do mesmo modo, a flexão temporal também é dividida em duas. A FLEXÃO TEMPORAL RICA desencadeia movimento v-para-T e não influencia no licenciamento do sujeito. A tipologia dada pelos autores, baseados em Koeneman \& Neeleam (2001), é aquela exposta em (1).

A tipologia apresentada mostra que a flexão rica está relacionada a traços fortes (nos moldes de CHOMSKY, 1995), desencadeando movimento visível. Essa tentativa é melhor que a chomskyana, de acordo com Biberauer \& Roberts (2010), uma vez que se pode eliminar o traço fraco e também o traço EPP em T que desencadeia movimento. Assim, a presença de um Tempo rico significa que um verbo finito não é um simples V, mas composto de elementos $\mathrm{V}$ e um $\mathrm{T}$ especificado. Esse composto deve se concatenar com $\mathrm{V}$ e com $\mathrm{T}$. A única maneira de satisfazer as propriedades do composto V+T é, primeiro, concatená-lo em $\mathrm{V}$ e então alçá-lo para T: o "movimento é desencadeado por traços inerentes de um elemento composto V+T"4 (BIBERAUER \& ROBERTS, 2010, p. 268, tradução nossa). Essa relação também inclui a marcação de aspecto e modo.

Em "a riqueza da morfologia temporal é o que subjaz o requerimento lexical para a formação desse elemento na Numeração" 5 (BIBERAUER \& ROBERTS, 2010, p. 268, tradução nossa), entendemos que, na Numeração, os verbos sintéticos ('farei', por exemplo) têm, pelo menos, [V+T] por um lado, e as construções perifrásticas ('vou fazer',

\footnotetext{
${ }^{4}$ Do original: Movement is thus triggered by the inherent features of the compound $\mathrm{V}+\mathrm{T}$ element.

5Do original: (...) richness' of tense morphology is what underlies the lexical requirement for the formation of such an element in the Numeration.
} 
por exemplo) apenas [V], por outro lado.

Tendo apresentado os aspectos essenciais do quadro proposto por Biberauer \& Roberts (2010) relacionado ao movimento do verbo em verbos sintéticos e perifrásticos, na próxima seção descrevo algumas propriedades da expressão de futuridade no PB dentro da diacronia e da sincronia.

\section{Tempo futuro no português brasileiro}

É comumente argumentado que o PB perdeu o movimento do verbo generalizado no fim do século XIX, de acordo com Matos \& Cyrino (2001), Cyrino \& Matos (2002), Cyrino \& Lopes (2016). Na verdade, parece ter havido perda de movimento no PB relacionado a muitos fenômenos linguísticos, como enfraquecimento da concordância (GALVES, 1993; 2001), novas estratégias de relativização (TARALLO, 1983), perda da ordem VS (BERLINCK, 1988), entre outros. Devido a isso, podemos considerar o século XIX como o século das luzes (cf. ARAÚJO-ADRIANO, 2019a) para a emergência de um português brasileiro ${ }^{6}$.

Especificamente relacionado ao movimento do verbo, no seu enfraquecimento temporal, Cyrino (2013) mostra que em um primeiro momento o PB seria considerado por Biberauer \& Roberts (2010) como uma língua de Tempo rico, uma vez que seu paradigma verbal deveria ser rico o suficiente (cf. (6)). Entretanto, muitas das formas verbais em (6) estão sendo substituídas por suas perífrases correspondentes, o que sugere que o paradigma temporal sintético no PB seja pobre, conforme apresentamos já no Quadro 1.

(6) como (presente do indicativo), comerei (futuro), comi (pretérito), comia (imperfeito), comera (mais-que-perfeito), comeria (condicional), comesse (passado subjuntivo), coma (presente subjuntivo).

Atentando-se ao Tempo futuro, Araújo-Adriano (2019a) mostra que o futuro

\footnotetext{
${ }^{6}$ Há um número considerável de trabalhos que mostram que o PB se tornou diferente do português europeu (PE) no fim do século XIX. Para os estudos fundantes sobre a emergência do PB, conferir os resultados reunidos em Kato \& Roberts (1993).
} 
sintético foi a estrutura de futuridade mais usada no PB durante os séculos XVI, XVII e XVIII e o começo do século XIX. Nesses períodos, a forma sintética (cf. (7a)) era usada juntamente da perífrase 'haver' + infinitivo (cf. (7b)). O próximo estágio foi promover outra forma perifrástica que veiculasse futuridade, 'ir' + infinitivo (cf. (7c)). Esse processo pode ser evidenciado pelos dados exibidos na Tabela 1, a seguir:

Tabela 1 - Futuridade pelos séculos

\begin{tabular}{|l|l|l|l|}
\hline Século & Sintética & Haver + infinitivo & Ir + infinitivo \\
\hline XVI & $71 \%$ & $29 \%$ & $\mathbf{0} \%$ \\
\hline XVII & $59 \%$ & $40 \%$ & $1 \%$ \\
\hline XVIII & $65 \%$ & $33 \%$ & $\mathbf{2} \%$ \\
\hline Começo do século XIX & $48 \%$ & $28 \%$ & $34 \%$ \\
\hline Fim do século XIX & $32 \%$ & $18 \%$ & $50 \%$ \\
\hline Começo do século XX & $21 \%$ & $4 \%$ & $75 \%$ \\
\hline Fim do século XX & $2 \%$ & $1 \%$ & $97 \%$ \\
\hline XXI & $1 \%$ & $\mathbf{0} \%$ & $99 \%$ \\
\hline
\end{tabular}

Fonte: elaborado pelo autor

(7) a. Onde irás.FuT-2p, meu coração, se aonde quer que tu fores, acharás.FuT-2s desgraça? (século XVIII).

b. Valha-te o Diabo, mofino, que sempre há-de.PRS-3s estar.INF de pachorra! (século XVIII).

c. Eu sempre vou.PRS-1s sentir.INF muito orgulho de ter sido apaixonado por você (século XIX).

Pensando na infância, Araújo-Adriano (2019b) mostra que as crianças brasileiras não adquirem a forma sintética em um contexto natural; i. e., de acordo com o autor, essa forma seria um produto do processo de escolarização, em que estruturas gramaticais velhas são recuperadas. Nesse sentido, somente a perífrase 'ir' + infinitivo estaria na L(íngua)-I da criança, sendo o futuro/evento potencial adquirido via regra em (8).

(8) Regra para o futuro/evento em potência em $P B$

Concatenar o item lexical IL carregando um traço categorial [+AUX] com um IL carregando um traço categorial $[+\mathrm{V}]$,

em que $[+\mathrm{AUX}]=$ 'ir'; e

$[+\mathrm{V}]=$ qualquer verbo no infinitivo. 
Se isso estiver no caminho correto, era de se esperar que qualquer verbo infinitivo fosse concatenado com o auxiliar 'ir' e transmitisse uma ideia de futuridade - o que parece ser o caso, em que não só o verbo 'ir' lexical (movimento) pode se concatenar com o auxiliar 'ir', como também qualquer verbo que esteja no infinitivo, como em "Eu vou[AUX] ir[VP infinitivo] ao cinema amanhã” e "Hoje eu vou[AUX] domingar[VP infinitivo]", respectivamente. No primeiro exemplo, seria um caso de "recursão", nos termos de Longo \& Campos (2002), enquanto o segundo mostra o verbo 'domingar' que é originalmente um dia da semana (transformar verbos a partir de dias da semana parece ser um fenômeno novo no PB, porém, para nosso propósito, é importante perceber que, havendo o auxiliar 'ir' e um infinitivo, a leitura de evento em potência é licenciada).

É interessante dizer que, na evolução das expressões de futuridade ao longo do tempo no $\mathrm{PB}$, o verbo 'ir' não "evoluiu” de lexical a auxiliar de futuridade diretamente. Antes de veicular um EVENTO POTENCIAL, 'ir' também veiculava PROSPECÇÃO, i.e., uma ação que acontece imediatamente depois da fala (cf. COMRIE, 1976; CINQUE, 1999). Um processo de gramaticalização ocorreu (cf. ARAÚJO-ADRIANO, 2019a), da seguinte forma: 'ir' lexical > 'ir' prospecção > 'ir' irrealis/futuro, como pode-se observar, a partir dos exemplos abaixo das peças analisadas.

(9) a. Agora vos digo.PRS-1s que vou.PRS-1s contente daqui.

b. Atenção! Mr. James vai.PRS-3s cantar.INF!

c. Ele vai.IRR-3s estudar na zona sul. Vai.IRR-3s morar.INF com a tia em Botafogo.

Assumimos por IRREALIS um traço que nucleia WollP, uma categoria imediatamente abaixo de TP (cf. WURMBRAND, 2007, 2014). Tal núcleo dispara uma leitura de evento em potência por um traço que proporciona à sentença uma leitura de 'não realizado', como sugerido por Abusch (2004), Lunguinho (2006, 2011) e Wurmbrand (2007, 2014). Elliott (2000), por exemplo, afirma que o traço IRREALIS veicula um evento que pertence ao domínio do imaginário e hipotético e, como tal, constitui ou um evento possível ou um evento potencial.

Assim, enquanto em (9a) o evento de 'ir' está acontecendo no presente (SM, RM, 
EM7) - o personagem da peça está se locomovendo, enquanto (9a) é falado -, em (9b) o evento não é hipotético, uma vez que há múltiplas evidências para a concretização da ação (Mrs. James está no palco, com um microfone, pronto para começar a cantar), portanto, quando (9b) é pronunciado, a ação de cantar é colocada em ação - esse é prototipicamente o traço prospectivo - uma ação que ocorre imediatamente após a fala (SM, RM_EM). Finalmente, (9c) mostra que o evento de morar é hipotético, está em planejamento, há potencial para ser concretizado, embora não haja nenhuma garantia de que a ação vá ocorrer com cem por cento de certeza. Por esse motivo, (9c) está instanciando um traço IRREALIS (SM_RM,EM).

Perceba que o IRREALIS pode ser vertido em um verbo sintético, em um contexto formal/escolarizado, como em "Ele estudará na zona sul”, mas esse não parece ser o caso para o prospectivo - a forma sintética não pode veicular prospecção, como em "Espera que vou espirrar” vs. “\#?Espera que eu espirrarei”8.

Uma vez apresentadas essas considerações iniciais sobre os dados diacrônicos, além da constituência sincrônica dos dados, na próxima seção apresento minha proposta para a diferença entre a forma sintética e a perifrástica de futuro no $\mathrm{PB}$, dentro da proposta de Biberauer \& Roberts (2010).

\section{Futuro sintético vs. perifrástico no PB: movimento do verbo}

Como proposto por Biberauer \& Roberts (2010), formas sintéticas são compostas por $[\mathrm{V}+\mathrm{T}]$ que desencadeiam movimento do verbo pela reprojeção de $\mathrm{V}$ em $\mathrm{T}$ para saturar seus traços inerentes. Assumindo os autores, sugerimos que, de fato, o futuro sintético tem um traço [V+Woll+T], pois como mostrado por Roberts (1993), o futuro românico foi originado da aglutinação de um verbo auxiliar 'habere' ('haver') ao verbo lexical. Nos textos latinos, a ordem de "habeo" + infinitivo era variável, permitindo que o auxiliar

\footnotetext{
${ }^{7}$ Na lógica representacional de Reinchebach (1947) e Hornstein (1990), SM é o momento da fala, RM é o momento da referência e EM é o momento do evento. A vírgula indica simultaneidade e o traço refere-se à precedência entre os tempos.

${ }^{8}$ Embora (i) "Já, já voltarei” e (ii) “Já voltaremos” tenham leitura de prospecção, neste artigo atribuímos essa leitura ao 'já', sustentando a análise aqui proposta.
} 
ficasse posposto, como em "cantare habeo", e também anteposto "habeo cantare". As formas pospostas deram origem ao futuro sintético românico (10a), enquanto as formas em que o auxiliar figurava depois do verbo deram origem ao condicional:

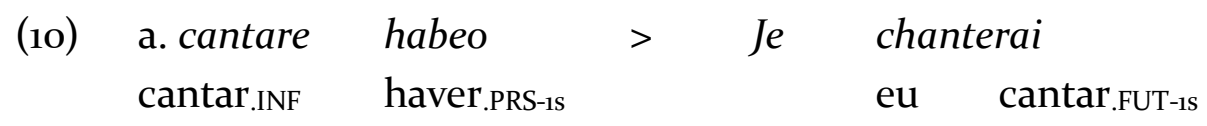

Devido a isso, a fim de manter a presença do significado IRREALIS de "habeo" no futuro sintético, parece fazer sentido postular que, de fato, o futuro sintético tem um traço Woll, que dá a ideia de evento em potência. Na verdade, há autores que inclusive consideram que o futuro sintético é a aglutinação do infinitivo ao habere, que passou a ser um afixo, após ser gramaticalizado (cf. ROBERTS, 1992).

Em termos operacionais, este artigo assume a proposta de Pesetsky \& Torrego (2007) para o sistema de valoração de traços de Chomsky (2000, 2001). Nela, um traço F pode ter ou não um valor $\alpha$ qualquer (quando valorado, $[\alpha]$, e quando não valorado, vazio [ ]) e pode ser interpretável (i) ou não interpretável ( $u$ ). Dessa combinação, chega-se ao arranjo em (A), a seguir.
(A) (i) F interpretável e valorado: $i F[\alpha]$.
(ii) $\mathrm{F}$ interpretável e não valorado: $i \mathrm{~F}[$ ].
(iii) F não interpretável e valorado: $u \mathrm{~F}[\alpha]$.
(iv) F não interpretável e não valorado: $u \mathrm{~F}[\mathrm{]}$.

Na esteira de Pesetsky \& Torrego (2007), em uma relação entre XP e YP, tal que X c-comanda $\mathrm{Y}$, o núcleo $\mathrm{Y}$ tem um traço uX não interpretável que participa de uma relação de Agree com o traço X de XP. Como X c-comanda Y, seu traço X deve ser uma sonda. Dessa maneira, $\mathrm{X}$ em XP deve ser um traço iX interpretável, não valorado, agindo como uma sonda. Igualmente, $\mathrm{X}$ em $\mathrm{Y}$ é um traço não interpretável que é valorado, agindo como um alvo. $\mathrm{O}$ traço não valorado deve ser apagado o mais rápido possível (esse apagamento é indicado por $u X)$, para que a estrutura convirja em LF.

$$
\text { Agree }
$$




$$
\begin{aligned}
& \begin{array}{llll} 
& \mathrm{X} & \ldots & {\left[{ }_{Y} \mathrm{Y}\right] \ldots}
\end{array} \quad \Rightarrow \quad \ldots \mathrm{X} \ldots\left[{ }_{Y} \mathrm{Y}\right] \\
& i \mathrm{X}[] \quad u \mathrm{X}[\alpha] \quad \quad i \mathrm{X}[\alpha] u \mathrm{X}[\alpha]
\end{aligned}
$$

Com isso em mente, assume-se a estrutura em (11) para o futuro sintético no PB:

(11) a. Seguirei sempre os teus passos

b. $\mathrm{N}=\left\{\left\{\right.\right.$ seguirei $\left._{([+\mathrm{V},+\mathrm{WOLL},+\mathrm{T}])}, \ldots\right\}$

c.

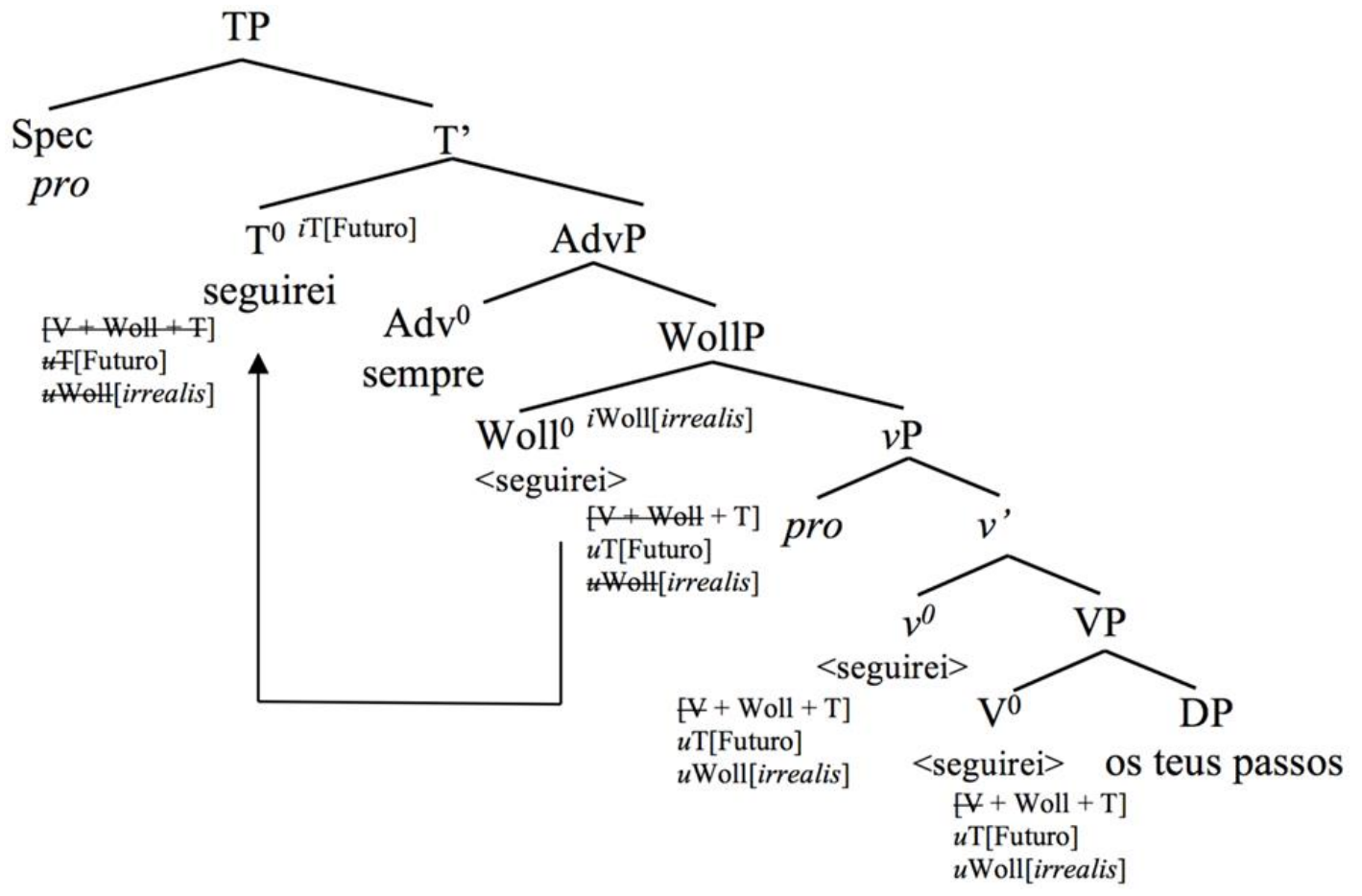

Em (11), o verbo primeiramente é concatenado em $V^{o}$, satisfazendo a parte $V$ do seu composto $[\mathrm{V}+\mathrm{Woll}+\mathrm{T}]$. Depois disso, V se move para $\mathrm{v}^{\mathrm{o}}$ (representado pelas chaves $<>$ ), dando seu papel temático para o DP. Sendo o núcleo da Fase (CHOMSKY, 20oo), v pode estabelecer uma relação de Agree com WollP, valorando como IRREALIS os traços $u$ Woll não valorados do núcleo Woll. Em seguida, o complexo V+Woll+T se move e parte do composto é saturado (representado em (11) pelo risco). Finalmente, o traço iT em T age como uma sonda e estabelece uma relação de Agree com seu alvo que porta traços $u T$ [FUTURO]. Após essa relação, o traço não interpretável $u \mathrm{~T}$ em $\mathrm{V}$ é apagado e o traço de $i T[$ ], até então não valorado, recebe o valor de FUTURO. Após essa relação, para formar TP, 
o composto [V+Woll+T] deve se mover para $\mathrm{T}^{\mathrm{o}}$. Nos moldes de Biberauer \& Roberts (2010), o movimento é desencadeado pelos traços inerentes da morfologia temporal rica presente em 'seguirei', uma forma sintética.

Um dos objetivos deste artigo é mostrar que o processo de analiticização ocasionou perda de movimento. Portanto, passemos agora a nossa proposta para as formas de futuro perifrástico e então algumas evidências que advogam em favor desta proposta (ver $§ 4$ ).

Assumindo que somente os tempos sintéticos têm no seu composto um T, que desencadeia v-para-T, consideramos que os núcleos auxiliares têm uma projeção AuxP hierarquicamente acima de vP. O auxiliar, então, viria da Numeração com esse traço AUX. Na verdade, afirmar que os auxiliares nucleiam um AuxP é somente uma questão de rotulação, uma vez que a generalização com que temos que lidar é que os auxiliares não fazem parte do VP, devido à falta de relação temática com os DPs argumentos.

Diante disso, 'ir', na nossa proposta, tem um traço AUX $(+\mathrm{V},-\mathrm{N}$, assim como um verbo "pleno") no seu composto que garante que será concatenado em um $\operatorname{Aux}^{0}$ e não em qualquer outro núcleo verbal (isso porque os auxiliares não participam de uma relação temática com os DPs argumentos). Uma vez que assumimos que a projeção WollP licencia uma leitura de evento em potência, esse auxiliar também tem um traço WOLL interpretado como IRREALIS em LF. À luz de Pesetsky \& Torrego (2007), 'ir' em Aux tem um traço uWoll[IRREALIS] e sua contraparte, WollP, tem um traço $i$ Woll[ ] não valorado.

Em (12), o verbo 'sentir' é primeiramente concatenado em Voopois disso, V se move para $\mathrm{v}^{\mathrm{o}}$ e atribui papel temático ao DP. Sendo o núcleo de uma Fase, v pode estabelecer uma relação de Agree com AuxP9 ${ }^{9}$. Devido a Woll ter um traço $i$ Woll[ ], ele age como uma sonda, ee, quando encontra um alvo perfeito (Aux que tem sua contraparte não interpretável), a relação de Agree ocorre: os traços não interpretáveis em AUX são checados e os traços interpretáveis, mas até então não valorados, em Woll, são valorados como [IRREALIS]. Portanto, já que da numeração, 'ir' vem portando traços [AUX+WOLL], a única maneira de satisfazê-los é por um movimento para o núcleo de Woll (representado em (12) pelas chaves <>). Além disso, na derivação, $\mathrm{T}$ é inserido e teria uma realização

${ }^{9}$ Nós não expandimos a análise da relação entre o complemento infinitivo e o auxiliar, porque isso extrapolaria os objetivos da nossa proposta. Porém, indica-se ao leitor Lunguinho (2006, 2011) e Resende \& Araújo-Adriano (2019). 
nula, somente agindo como um núcleo que checa nominativo (cf. BIBERAUER \& ROBERTS, 2010, p. 280). Nesse sentido, o movimento é desencadeado por traços inerentes do composto [AUX+WOLL].

(12) a. Eu sempre vou sentir muita falta de você

b. $N=\left\{\left\{\operatorname{vou}_{([+A U X,+W O L L]}\right), \ldots\right\}$

c.

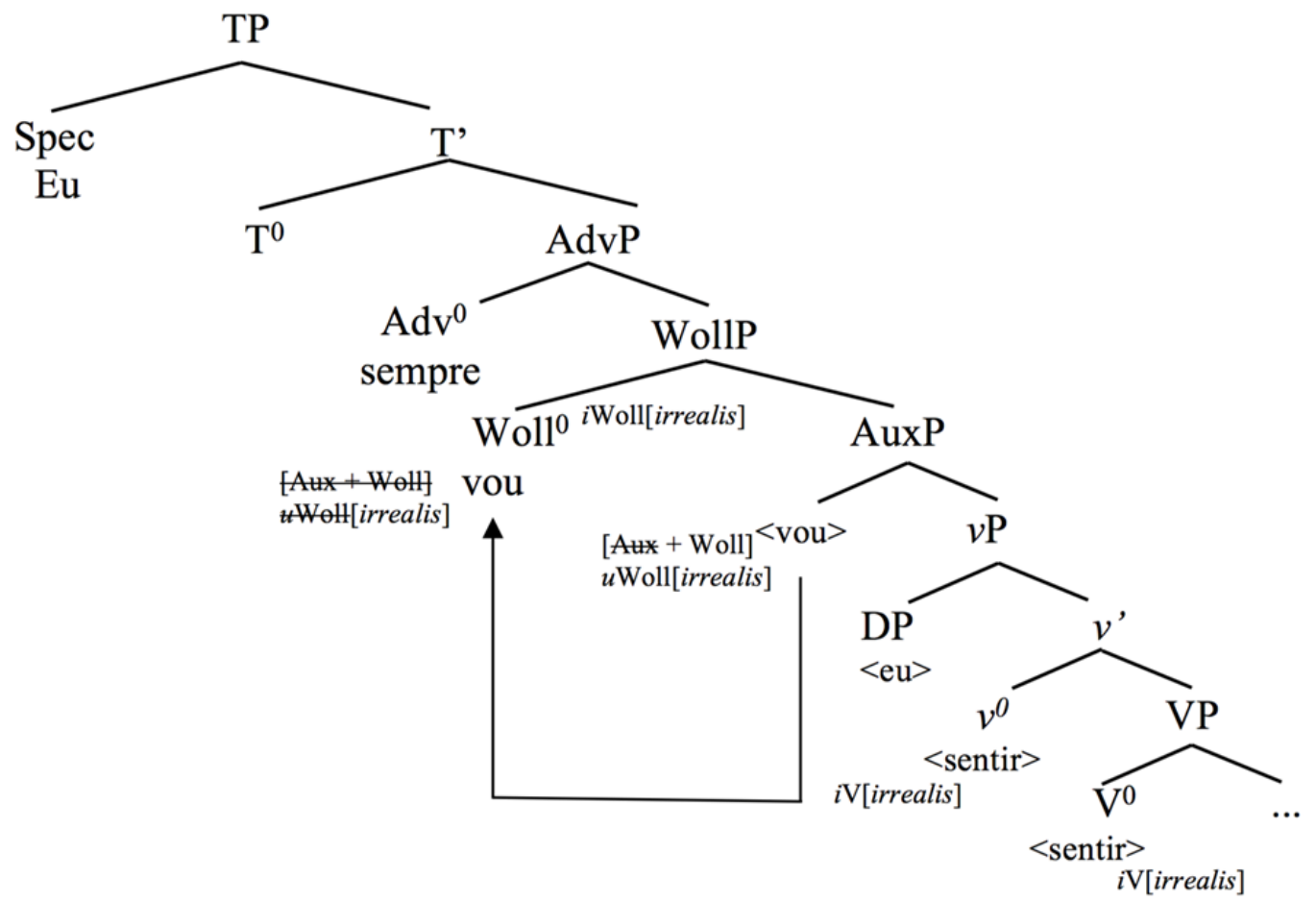

O auxiliar não deve ser diretamente inserido na zona TAM (Tempo, Modo e Aspecto), como propõem Roberts \& Roussou (2003), uma vez que é a primeira concatenação que garante que haverá paralelismo entre o local de identidade e o verbo, em se tratando de elipse de VP. Cyrino e Matos (2005), por exemplo, mostram que o alçamento do verbo (principal ou auxiliar), por deixar uma cópia que é interpretada como um elemento do predicado, previne a agramaticalidade de (13):

(13) *Ele trabalhava até tarde e nós também ficávamos [-]

[-][ficávamos] a trabalhar/trabalhando até tarde

Nesse modelo, assumindo que os auxiliares são gerados em VP/vP, o que garante que o sistema computacional, por exemplo, atribua a (14) o contraste encontrado entre 'ir' 
com traços aspectuais (14a) (prospectivo, com uma leitura em que a ação ocorre imediatamente após a fala:SM,RM_EM), e (14b), uma sentença com a leitura de um evento em potencial veiculado pelo traço IRREALIS (SM,RM_EM), é a projeção funcional para onde 'ir' se move: (i) a leitura de prospecção é licenciada pela relação entre o auxiliar 'ir' e o núcleo aspectual, enquanto (ii) a leitura IRREALIS é licenciada pela relação entre 'ir' e WollP:
(14) a. Calma que eu [Asp ${ }^{\circ}$ vou [vou espirrar!]
b. Eu acho que [Woll ${ }^{\circ}$ vou [vou prestar o concurso do TRE]

Nas próximas seções, apresento algumas evidências para minha proposta, considerando a sintaxe do advérbio 'sempre', o esvaziamento semântico do futuro sintético e a elipse de VP.

\section{Evidência para nossa proposta: A sintaxe de 'sempre'}

A primeira evidência que apresentamos está relacionada à sintaxe do advérbio 'sempre'. Araújo-Adriano (2019a), analisando dados diacrônicos, mostra que, enquanto a estrutura sintética estava presente no sistema do PB, o ordenamento de 'sempre' era diferente do ordenamento desse advérbio quando a perífrase se consolidou (cf. (16) mais a frente). Esse dado, de fato, parece dizer algo sobre movimento do verbo, uma vez que de acordo com Brito (2001), Cyrino (2013), Reintges \& Cyrino (2018), o advérbio 'sempre' pode delimitar movimento devido ao fato de que há dois ordenamentos possíveis em 
português: a posição pós-verbal $\left(\mathrm{PE}, \mathrm{PB}^{\star / \# 10}\right)$ e a posição pré-verbal (PE, $\left.\mathrm{PB}\right)$. $\mathrm{O}$ último ordenamento, no PB, pode somente haver uma leitura temporal, como "eternamente", enquanto em PE a leitura obtida é a de valor confirmativo, tal como "de fato". Os seguintes exemplos ilustram esse contraste (BRITO, 2001, p. 66):
a. Eu encontro sempre o Luís no café (temporal / aspectual 'sempre')
b. Eu sempre encontro o Luís no café (temporal / aspectual 'sempre')
c. Eu sempre encontrei o Luís no café (confirmativo 'sempre')

Em relação ao posicionamento de 'sempre' na expressão de futuridade, o português brasileiro mostra um interessante contraste ao longo da história, como revelam os dados diacrônicos de Araújo-Adriano (2019a):
(16) Sintético
$12 \%$ sempre-V
93\% V-sempre
Ir + infinitivo
$88 \%$ sempre-V
7\% V-sempre

Assim, assumimos que 'sempre' está c-comandado por TP. A derivação das estruturas sintéticas e perifrásticas ocorre da mesma forma que as apresentadas em (11) e (12). Entretanto, com 'sempre' c-comandado por TP"1 , deriva-se a preferência pela ordem 'sempre’_V no PB (o que já foi atestado anteriormente por AMBAR et al., 2004; CYRINO,

\footnotetext{
${ }^{10}$ Muito embora Galves (2001) tenha mostrado haver opcionalidade no posicionamento do advérbio 'sempre' em PB, alguns trabalhos recentes têm atestado haver certa preferência pelo advérbio anteposto ao verbo (cf. BRITTO, 2001, CYRINO, 2013, REINTGES \& CYRINO, 2018). Para um parecerista anônimo, (15b) não é ruim, porém seria uma sentença marcada, com preferência para (15a). Agradecemos ao julgamento e, levando isso em consideração, uma ideia então seria propor que esse ordenamento não preferencial é desencadeado por regras sintáticas que comporiam a periferia marcada. Como AraújoAdriano (2019a) e o exemplo (16) mostram, enquanto a forma sintética fazia parte do sistema, o ordenamento $\mathrm{V}$-sempre ainda era produtivo, derivado por meio do movimento de $\mathrm{V}$ para $\mathrm{T}$ e, com a emergência da perífrase, tal ordenamento deixou de ser produtivo. Assim, uma vez que regras e estruturas antigas da língua podem não fazer parte da Gramática Nuclear do falante, mas da sua Gramática Periférica (cf. CHOMSKY, 1981; KATO, 1999, 2005, 2013), uma proposta seria pressupor que nessa última, para alguns falantes, ainda há resquícios de regras de movimento de $\mathrm{V}$ para $\mathrm{T}$ que licenciam tanto a forma sintética, quanto o ordenamento não preferencial do advérbio. Em relação à ideia de que a forma sintética faça parte da gramática periférica do falante de $\mathrm{PB}$, Araújo-Adriano (2019b, no prelo) mostra que crianças adquirindo as expressões de futuridade não produzem forma sintética. Essa forma só vai ser adquirida ao longo da escolaridade em textos escritos, pois, na fala, a perífrase é praticamente categórica. Isso sugere que a escola estaria recuperando formas antigas da língua (forma sintética), sendo licenciadas por regras sintáticas datadas, na Gramática Periférica, o que poderia também ser o caso da "opcionalidade" da ordem de 'sempre'.

"Outra maneira de implementar essa análise é adjungir 'sempre’ a T2, no sistema de Giorgi \& Pianesi (1997), usado por Cyrino (2013).
} 
2013; REINTGES \& CYRINO, 2018).

Figura 1 - Contraste entre as estruturas sintéticas e perifrásticas de futuridade em relação ao advérbio 'sempre'

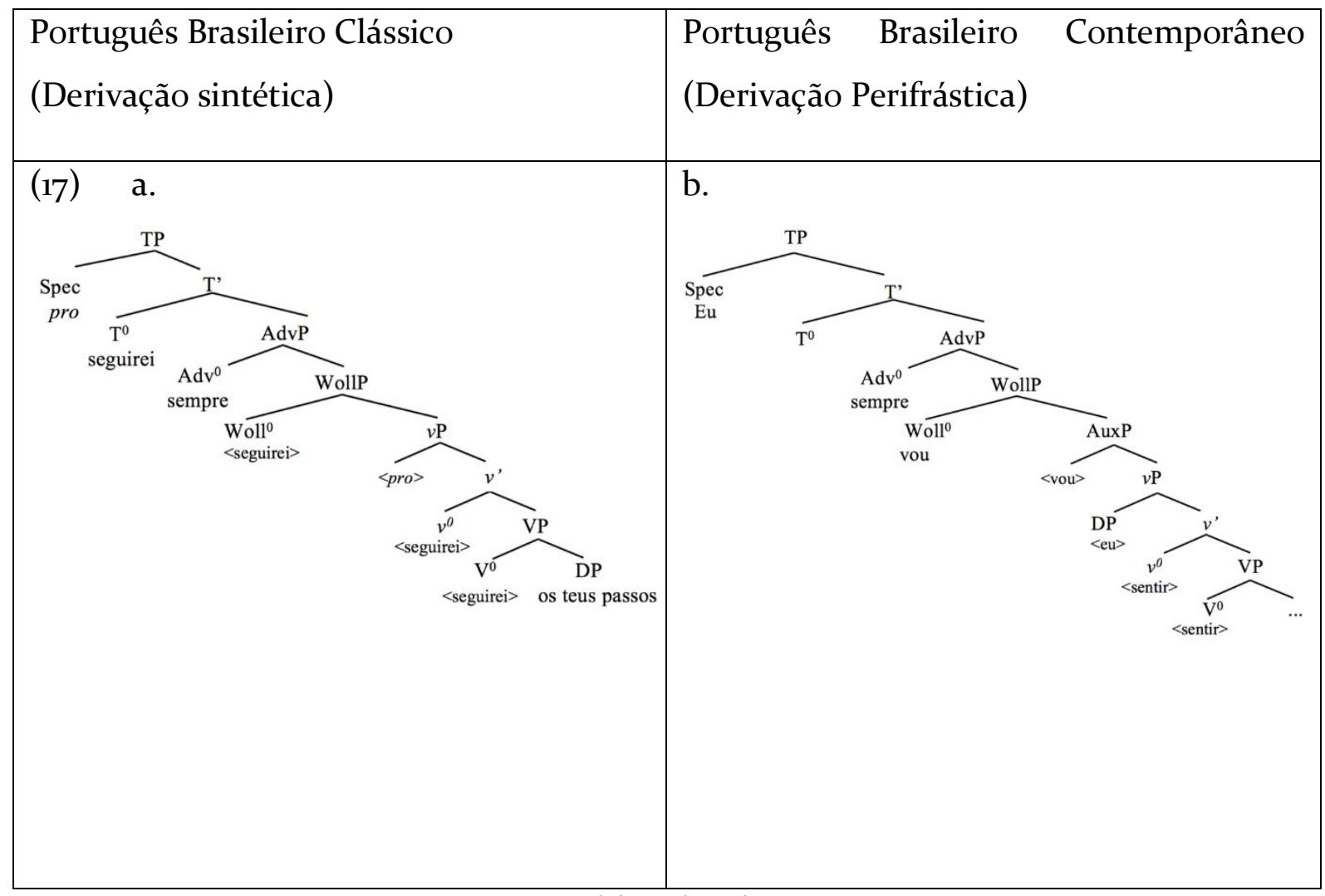

Fonte: elaborado pelo autor

Em (17a), até o século XVIII, a forma sintética tinha que se mover até TP, para não só saturar os seus traços inerentes do composto [V+Woll+T], como também para checar traços de concordância (se não assumimos uma posição AgrP como na análise de GALVES, 1993), quando o PB tinha concordância rica ${ }^{12}$. Porém, perdendo o movimento do verbo

\footnotetext{
${ }^{12} \mathrm{Na}$ verdade, Araújo-Adriano (2019a) mostra que enquanto a forma sintética existiu a concordância ainda era rica: havia seis formas para o paradigma da concordância (cf. GALVES, 2001). Entretanto, quando a forma sintética deixou de ser produtiva, o paradigma se reduziu a quatro formas, ou seja, em relação ao dados, foi possível atestar uma mudança no empobrecimento verbal não só no que se refere à concordância, como também no empobrecimento temporal:

[+ pessoa; - número] >-o (canto)

[+ pessoa; + número] >-mos (cantamos)

[- pessoa; + número] >-m (cantam)
} 
generalizado (CYRINO \& LOPES, 2016; MATOS \& CYRINO, 2001; e.o.), no século XIX, a forma sintética perdeu seus traços $\mathrm{T}$ (como vamos argumentar na próxima seção), não havendo mais necessidade de se mover para T (cf. 13b). Como consequência, a ordem gerada é aquela a que os falantes de PB preferem: sempre_V, como mostrado em (17).

\section{O esvaziamento do sentido de futuro}

A estrutura sintética praticamente não existe mais no português falado, como podemos ver na Tabela 1 (cf. também OLIVEIRA, 2006; ARAÚJO-ADRIANO, 2016, 2019a). Assim, o movimento esboçado em (11) e (17a) não existe ${ }^{13}$ mais nessa língua, no domínio oral. Interessantemente, há algumas formas sintéticas ainda presentes no domínio oral, mas que não veiculam futuridade, como vemos em (18), abaixo:

(18) a. O que será que aconteceu?

b. Mal falo português, quem dirá inglês!

c. Se ela que é rica reclamou de comprar o ingresso, que dirá eu!

d. Paulo, vá arrumar teu quarto! Aquilo lá está ao Deus dará!

e. Será o benedito que não tem uma série e um filme que chame minha atenção nessa netflix?

Em (19) vemos que as formas acima não são equivalentes a sua perífrase, o que sugere que elas não veiculam, pois, futuridade.

(19) a. *O que vai ser que aconteceu?

b. *Mal falo português, quem vai dizer inglês!

c. *Se ela que é rica reclamou de comprar o ingresso em 20 parcelas, que vai dizer eu!

d. *Paulo, vá arrumar teu quarto! Aquilo lá está ao Deus vai dar!

e. ${ }^{*}$ Vai ser o benedito que não tem uma série e um filme que chame minha atenção nessa Netflix?

[- pessoa; - número] >-o (canta)

${ }^{13}$ Araújo-Adriano (2019a, 2019b, no prelo) mostra que a escolarização tem um papel importante em relação à recuperação do fóssil futuro sintético, dos séculos XVI-XIX. Nesse sentido, na periferia marcada, o movimento v para T seria licenciado, para derivar (11). Para uma discussão sobre Gramática Periférica, conferir também Nota 11. 
Juntamente a isso, exceto pelos exemplos (18d) e (19e), que realmente parecem ser uma expressão idiomática; os exemplos em (18a-c) ocorrem somente em um contexto CP e especificamente com determinados verbos (lexicais):

(20) a. O que será/(`falará) [CP que aconteceu?

a'. O que será *(que) aconteceu?

b. Mal falo português, quem dirá/( ${ }^{*}$ falará) inglês!

b'. Mal falo português, ${ }^{\star}($ quem$)$ dirá português

c. Se ela que é rica reclamou de comprar o ingresso, que dirál(“*omprará) eu!

c'. Se ela que é rica reclamou de comprar o ingresso, *(que) dirá eu!

Diante disso, parece que as únicas estruturas de futuro sintético atestadas no PB contemporâneo perderam significado temporal. Como consequência, o verbo perdeu seu movimento para checar somente traços IRREALIS. O significado de futuridade é derivado a partir de um traço IRREALIS. Uma vez que o futuro não é veiculado por uma estrutura sintética, nós poderíamos argumentar que o português brasileiro, pelo menos morfologicamente, é uma língua passado vs. não passado ${ }^{14}$.

\section{Elipse de VP}

A elipse de VP é um fenômeno que ocorre quando um constituinte sintático é omitido sob identidade com um antecedente no discurso (cf. CHOMSKY, 1965; ROSS, 1967, 1969, entre outros). Jackendoff (1971), por exemplo, salienta que a elipse de VP opera pelo menos nos verbos e nos seus complementos; opcionalmente, a elipse pode também operar em um modificador restritivo. Entretanto, o que não é opcional é o escopo da operação: a elipse de VP não pode operar em um V sozinho:

(21) a. *Mary will meet Bill at Berkeley because she didn't [-] John. [-] meet

b. Mary will meet Bill at Berkeley because she didn't [-] at Harvard.

\footnotetext{
${ }^{14}$ Lembre-se de que o paradigma da analiticização no PB é organizado com o auxiliar ou flexionado no presente ou no passado (cf. Quadro 1).
} 


\section{[-] meet Bill \\ c. Mary will meet Bill at Berkeley because Sue didn't [-]. [-] meet Bill}

É necessário que a elipse de VP ocorra em uma projeção de V. Quando o verbo se move para a zona TAM, onde o verbo licencia a elipse de todo o VP, o verbo deixa um vestígio fonologicamente nulo para trás. Dessa forma, o local de elipse deve ser ccomandado pelo verbo. De acordo com Johnson (2001), os auxiliares, por exemplo, precisam estar na projeção funcional mais alta para que o licenciamento da elipse ocorra ${ }^{15}$.

Agora, foquemo-nos na elipse de VP em português. Dentre as línguas românicas ${ }^{16}$, somente o português europeu e o brasileiro podem elidir o VP. Cyrino (2006) argumenta que os auxiliares e os verbos principais podem licenciar elipse de VP pelos exemplos em (22), em que é possível ver que, quando o verbo se move para a zona TAM, um vestígio é deixado.

(22) a. Ana trouxe o computador para a faculdade hoje e a Paula também trouxe [-].

[-] = [trouxe o computador para a Faculdade hoje]

b. Ela está enviando o livro para a editora e ele também está [-].

$[-]=$ [está enviando o livro para a editora $]$

Entre o PE e o PB há algumas diferenças que fizeram Matos \& Cyrino (2001) e Cyrino \& Matos (2002) assumirem que a projeção funcional que licencia a elipse de VP é, na primeira língua, $\mathrm{T}$, enquanto na última, pode ser qualquer projeção funcional abaixo de T. As autoras chegam a essa conclusão baseadas no comportamento do advérbio

${ }^{15}$ Para saber o que a elipse de VP pode fazer, e o que não pode, cf. Johnson (2001).

${ }^{16}$ Cyrino \& Matos (2002) mostram que a elipse de VP não é possível em francês, tampouco em espanhol:

(i) *Susana había leído Guerra y Paz pero María no había [-].

'Susana tinha lido Guerra e Paz, mas Maia não tinha [-]'

(ii) * On a demandé si ils ont déjà mangé et ils ont [-]

'Perguntamos se eles já tinham comido e eles não [-]'

(iii) *Claudine est une bonne étudiante, et Marie est aussi.

'Claudine é um bom aluno, e Marie é também’ 
'também', como mostrado em (23):

(23) a. O João tinha lido o livro às crianças e a Maria também tinha lido [-]
[-] o livro às crianças
$(\sqrt{ } \mathrm{EP}, \sqrt{ } \mathrm{BP})$

b. O João tinha lido o livro às crianças e a Maria tinha lido [-] também

[-] o livro às crianças $\quad\left(\sqrt{ } / ?^{17} \mathrm{EP}, \sqrt{ } \mathrm{BP}\right)$

c. O João tinha lido o livro às crianças e a Maria tinha também lido [-]

[-] o livro às crianças $\quad$ (\% EP, $\sqrt{ } \mathrm{BP})$

Uma vez que 'também' é necessário para a elipse de VP veicular explicitamente a identidade do conteúdo elidido, (23) mostra que em PE a posição de 'também' é muito mais restritiva. De acordo com Cyrino (2013), quando 'também' intervém entre T e VP18 em PE, a elipse não pode ser recuperada (o símbolo \% em (23c) sinaliza que a sentença em $\mathrm{PE}$ não veicula a leitura da elipse de $\mathrm{vP}$ como primeira leitura, conforme discutido por CYRINO \& MATOS, 2002; CYRINO, 2013). Entretanto, em (23a), quando 'também' está focalizando o verbo em T, a elipse é concebida, o mesmo valendo para (23b), em que 'também' segue todo o vP. Além disso, quanto ao $\mathrm{PB}$, Cyrino aponta que é uma projeção funcional mais baixa que T, onde 'lido' está posicionado, que licencia a elipse de VP, como em (23c), diferentemente do PE.

Seguindo esse raciocínio, uma vez que nossa proposta advoga em favor de o futuro perifrástico não se mover para $\mathrm{TP}$ em $\mathrm{PB}$, isso poderia prever algumas generalizações sobre a elipse de VP. Lembremo-nos de que Cyrino \& Matos (2002) propuseram que a projeção funcional que licencia elipse em PE "deve ser $\mathrm{T}^{\circ}$, ou a interpretação da elipse de VP é perdida; em PB [a projeção funcional] deve ser qualquer núcleo funcional abaixo de $\mathrm{T}^{\mathrm{o}}$ ". Se nossa análise estiver no caminho correto, e a proposta de Cyrino \& Matos (2002) e

\footnotetext{
${ }^{17}$ Cyrino (2006) considera a sentença abaixo em (i), com o advérbio 'também' no fim da sentença, semelhante a (23b), como marginal, porém em Cyrino (2013), (23b) é considerada boa. Em Cyrino (2006), a autora assume que 'também' precisa c-comandar todo o complexo verbal e, uma vez que em (i) não há c-comando, a autora considera-a como marginal. Em contrapartida, em Cyrino (2013) é assumido somente uma questão de interveniência: 'também' não pode intervir entre T e VP em PE; assim, como em (23b) não há interveniência, Cyrino julga-a como gramatical.

(i)?O João não faz isso antes de a Maria ter feito [-] também.

${ }^{18}$ Cyrino (2013) assume uma abordagem baseada em Giorgi \& Pianesi (1997), em que T é expandido em T1 e T2. No caso da elipse, no PB, T2 (aspecto e modo) é o local licenciador, enquanto que em PE, T1 é a projeção funcional que permite elipse de VP.
} 
Cyrino (2013), é esperado que possamos encontrar elipse de VP em contextos em que a posição para onde o verbo se move é Wollo ${ }^{\circ}$ TP > WollP), i.e., uma posição abaixo de TP:

(24) a. As mulheres vão assar bolo para a festa e os homens não vão [-]

[-] e os homens não [Woll ${ }^{\circ}$ vãoi [vp/Auxp vã $\Theta_{i}$ assar bolo para a festa]

b. As mulheres vão assar bolo para a festa e os homens também vão [-].

[-] e os homens também [Woll ${ }^{\circ}$ vão $\mathrm{O}_{i}$ [VP/AuXp-vãoi-assar bolopara a festa]

Em (24), percebemos que a elipse de VP é recuperada em um contexto perifrástico de futuridade, uma vez que o verbo se move para a projeção funcional mais baixa que TP. De acordo com Cyrino \& Matos (2007), o parâmetro da elipse de VP é estabelecido da seguinte forma:

(25) A elipse de VP é licenciada sob c-comando local por um núcleo funcional com traços-V que se concatena com ele.

Seguindo (25), haver c-comando local por um núcleo funcional V é necessário para licenciar a Fase vP como uma projeção verbal completa. Cyrino \& Matos (2005, p. 95) afirmam que isso ocorre, no caso do português, pelo movimento de V: "o vP elíptico é adicionalmente licenciado por c-comando local do verbo alçado". As autoras ainda argumentam que (25) é necessário, mas não é suficiente, pois faria previsões incorretas de que algumas línguas com movimento do verbo generalizado teriam elipse de VP - de fato, o espanhol, francês e italiano não mostram elipse de VP. Devido a isso, Cyrino \& Matos (2007, p. 202) também mostram que o processo de gramaticalização é um processo importante para a elipse de VP quando afirmam que "o enfraquecimento de valor aspectual está correlacionado com a perda de valor temporal da flexão verbal que afeta o auxiliar”. Baseado nisso, no francês e no espanhol ${ }^{19}$, cujas formas verbais estão altamente gramaticalizadas, Asp está muito próximo de tempo (T) e, por isso, é interpretado com

\footnotetext{
${ }^{19}$ Mesmo que os auxiliares no francês e no espanhol exibam um afixo no tempo presente, a forma verbal composta [AUX $X_{\text {resente }}+$ Particípio] é interpretada como passado e pode ser usada como passado simples:

(i) Jean a vu ses amis.

'Jean viu seus amigos'

(ii) Juan ha visto a suyos amigos.

'Juan viu seus amigos'
} 
parte de vP (ver (26a)). Por outro lado, línguas cujas formas complexas mantêm seu valor, AspP é entendido como uma projeção estendida do predicado vP, formando um complexo AspP_vP (cf. (26b)):

$$
\begin{aligned}
& \text { a. }\left[{ }_{\mathrm{CP}} \mathrm{C}\left[{ }_{\mathrm{TP}} \mathrm{T}\left[\text { Asp } \ldots\left[{ }_{\nu \mathrm{P}}\right]\right]\right]\right] \\
& \text { b. }\left[{ }_{\mathrm{CP}} \mathrm{C}\left[{ }_{\mathrm{TP}} \mathrm{T}\left[\text { Asp-vP Asp-vP } \ldots\left[{ }_{\nu \mathrm{P}}\right]\right]\right]\right]
\end{aligned}
$$

Lembremo-nos de que (25) afirma que um c-comando local é necessário. Assim, Cyrino \& Matos (2005) levam a propor que a diferença paramétrica entre as línguas que têm movimento de $\mathrm{V}$ é a \pm disponibilidade de c-comando imediato do predicado elidido por uma projeção funcional licenciadora. Além disso, explicam a diferença entre o português, o francês e o espanhol: "isso acontece em PE, uma vez que T se concatena com Asp-vP, assim como no $\mathrm{PB}$, em que o licenciador verbal deve ocorrer em $\operatorname{Asp}(\mathrm{P})$ ou Pass $(\mathrm{P})$, já que essas categorias devem se concatenar com $\mathrm{vP}$, satisfazendo o requerimento de c-comando imediato" (CYRINO \& MATOS, 2016, p. 315), como pode ser visto por (26b). Não obstante, o quadro não é o mesmo para o francês ou o espanhol, uma vez que Asp é um interveniente entre T e vP (cf. (26b)).

Assumindo essas considerações sobre a questão paramétrica e a potencial projeção funcional licenciadora, podemos agora retornar aos nossos propósitos. Lembremo-nos de que em (24) vimos que o contexto de futuridade é capaz de recuperar elipse de VP. Como já vimos, a elipse de VP ocorre sob duas máximas: (i) c-comando local e (ii) gramaticalização fraca do auxiliar. Primeiramente, discutamos o primeiro caso.

Em relação à gramaticalizacão do verbo 'ir', é possível perceber que ele não está totalmente gramaticalizado. Seguindo os critérios propostos por Longo \& Campos (2002) e a classificação aspectual de Vendler (1967), Rech (2013) investigou o quão gramaticalizados os verbos 'ir' e 'ter' estão. Para nosso propósito, Rech (2013) mostrou que 'ir' não está integralmente gramaticalizado, pois não passa em dois testes (x) inseparabilidade; $(\sqrt{ })$ irreversibilidade; $(\sqrt{ })$ esvaziamento semântico; $(\sqrt{ })$ recursão e $(\sqrt{ })$ perda das características sintáticas; ( $\mathrm{x}$ ) incompatibilidade com todas as classes 
aspectuais $^{20}$. Ademais, Lobato (1975) mostra que 'ir' não é compatível com todas as propriedades de um auxiliar. Assim, assumimos que 'ir' não está totalmente gramaticalizado ${ }^{21}$.

A partir disso, juntando o exposto até agora com a proposta de Cyrino \& Matos (2005), podemos assumir que 'ir' mantém seu valor IRREALIS, o que nos leva a afirmar que WollP deveria ser entendido como uma projeção estendida do predicado vP, formando um complexo WollP_vP.

Portanto, o licenciamento da elipse de VP no contexto de futuridade ocorre quando T se concatena com WollP_vP, que poderia ser o licenciador verbal. Uma vez que vP deve se concatenar com WollP para satisfazer seu composto ( $\mathrm{cf}$ § 3), ele também satisfaria o requerimento de c-comando imediato exposto em (25). Observe:

(27) a. As mulheres vão.PRS-3s assar.INF bolo para a festa e os homens também vão.PRS-3s [-]

b.

\footnotetext{
${ }^{20}$ Lunguinho (2011) mostra que 'ir' é um auxiliar, mas reconhece que a compatibilidade com a classe aspectuais deve ser um critério para definir o quão gramaticalizado um verbo está.

${ }^{21}$ Uma importante restrição na análise de Lunguinho (2006, 2011) é que os auxiliares mostram dependência morfossintática. Para o autor, cada auxiliar ('estar', 'ter', 'ser', 'ir') seleciona necessariamente um complemento verbal ([verbo auxiliar] $\rightarrow$ [verbo na forma nominal $\alpha]$ ). Assim, a dependência ocorre da maneira como se segue:

(i) [estar] $\rightarrow$ [gerúndio]

(ii) [ter] $\rightarrow$ [particípio]

(iii) $[$ ser] $\rightarrow$ [particípio]

(iv) [ir] $\rightarrow$ [infinitivo]
}

Uma vez que essa éuma restrição determinante para o autor, o seguinte exemplo seria um contra argumento para o esquema acima, em que o verbo 'ir' aparece com um complemento gerúndio:

(v) Até mais, a gente vai se falando

O exemplo em (v) sugere que, além de Rech (2013), Lobato (1975), o auxiliar 'ir' não está em uma situação clara se está total ou parcialmente gramaticalizado. 


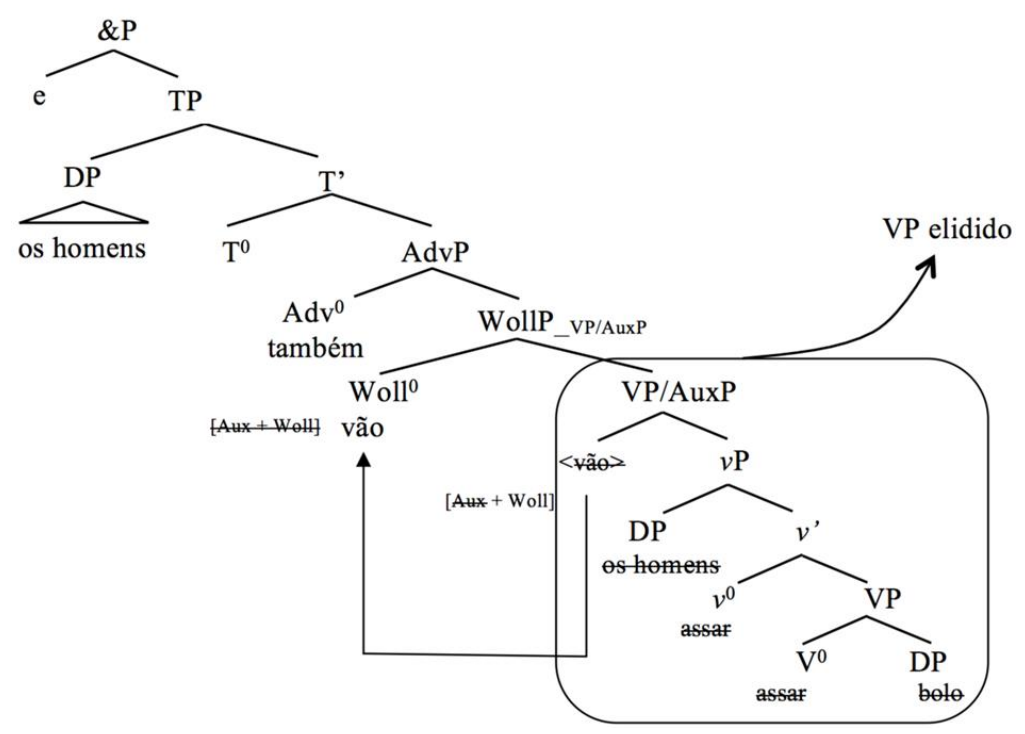

Alguém poderia contra-argumentar que o PB pode recuperar elipse de VP com a estrutura de futuro sintético. De fato, isso é verdade, se olharmos para os exemplos em (28). Porém, uma vez que mostramos que o futuro sintético não existe mais no $\mathrm{PB}$, como apresentado na Tabela 1, podemos argumentar que esse movimento também não existe mais, pelo menos na fala.

(28) a. A Maria lerá.FUT-3s os livros para as crianças e o João também lerá.FUT-3s [-].

[-] o João também [ $\mathrm{T}^{\mathrm{o}}$ lerái [lerái-os livros para as crianças]

b. Os homens organizarão.fuT-3s as contas para o Imposto de Renda e as mulheres também organizarão.FUT-3s [-]

[-] as mulheres também [ $\mathrm{T}^{\mathrm{o}}$ organizarão [өrganizarã $\Theta_{\mathrm{i}}$ as contas para $\Theta$ Imposto de Renda]

Se nossa proposta estiver no caminho correto, nós conseguimos explicar o porquê de em (28) a elipse ser recuperada. Quando Cyrino \& Matos (2002) afirmam que a diferença entre o PE e o PB é o licenciador da elipse, em que no primeiro é sempre T, e no último qualquer projeção funcional abaixo de $\mathrm{T}$, elas também afirmam que pode ter ocorrido alguma mudança diacrônica no PB que levou todas as projeções funcionais a serem reanalisadas como projeções estendidas de V. Portanto, nós vimos que o processo de analiticização de futuridade é um exemplo dessa mudança diacrônica.

Quando o futuro sintético ainda fazia parte do sistema do $\mathrm{PB}, \mathrm{T}^{\mathrm{o}}$ se comportava do mesmo modo que em PE: T poderia licenciar elipse de VP, como visto por (28). Porém, 
lembre-se de que o processo de analiticização reduz o movimento do verbo, assim como vimos anteriormente (o futuro sintético movia-se para Woll e, em seguida, para T, enquanto o futuro perifrástico se move somente para Woll). Relacionado à elipse de VP, esta é exatamente a conclusão a que chega Cyrino \& Matos (2002, p. 193) sobre a diferença entre o PB e o PE: "nós hipotetizamos que essa mudança se relaciona com outra: a perda irrestrita do movimento do verbo generalizado nessa variedade do português".

Em síntese, enquanto a forma sintética era produtiva no $\mathrm{PB}$, $\mathrm{T}$ licenciava elipse de VP. Entretanto, com a analiticização em jogo, o significado temporal foi reduzido a uma interpretação aspectual-modal (mais baixo que T). Nesse sentido, outras projeções funcionais foram reanalisadas ${ }^{22}$, permitindo-as elidirem um VP, por exemplo.

\section{Considerações finais}

Neste artigo, advogamos que uma leitura futura no PB agora tem somente traços relacionados a modo - não há reprojeção em T. Pelo processo de analiticização, o PB perdeu sua forma sintética, dando espaço para a estrutura perifrástica. Entretanto, não parece haver uma relação entre o movimento de $\mathrm{V}$ e se uma língua tem ou não um tempo sintético, como proposto por Biberauer \& Roberts (2010).

Como defendemos, o PB é uma língua com morfologia de futuro pobre e ainda apresenta movimento parcial do verbo. No fim do século XIX, o futuro sintético foi perdido na língua; alguns resíduos de sintético não veiculam mais propriedades temporais. Nós propusemos que somente a ativação de irrealis é necessária para veicular a ideia de um evento em potência.

Assumindo uma estrutura expandida em T > Woll > Asp, é possível perceber que a perda do movimento do verbo está relacionada somente à perda do movimento do verbo

\footnotetext{
${ }^{22}$ Pode ser o caso de outra projeção funcional, a saber AspPProgressivo, ter sido reanalisada dentro do processo de analiticização do tempo presente no PB. Araújo-Adriano (2019c) mostra que no século XVIII o presente simples era mais usado para veicular simultaneidade à fala, enquanto no século XXI esse não é o padrão: a perífrase parece ser necessária, enquanto o presente simples, no mesmo contexto, é minimamente estranho:

(i) Eu estou pasmada! Que diabo é isto que vejo.prs-s?

(século XVIII)

(ii) Eu estou pasmada! Que diabo é isto que estou.AUX-s vendo.GER ( ${ }^{*}$ vejo)?

(século XXI)
} 
a projeções mais altas. A forma sincrética tempo-modo no futuro do PB é reanalisada como uma forma puramente de modo (cf. também ARAÚJO-ADRIANO, 2019a). No caso do futuro nessa língua, uma especificação de traço original [+IRREALIS, +TEMPO] foi reduzida a [+IRREALIS]. Isso desencadeia uma restrição do escopo do movimento: T não está mais disponível para o pouso do verbo, mas sim o núcleo WollP (IRREALIS) (ou também o núcleo AspP, como no contexto de prospecção, visto em (14a)).

Assim como argumentado por Cyrino (2013) para o passado simples, este artigo mostrou que o movimento do verbo não está relacionado à riqueza do paradigma sintético, mas ao conteúdo semântico de IRREALIS (WollP) / Tempo (TP). Quando a forma sintética tinha uma interpretação temporal/modo, o verbo subia para os núcleos semanticamente associados, a fim de ter seus traços compostos checados/valorados/deletados. Uma vez que (i) a forma sintética perdeu seu significado temporal (no fim do século XIX), (ii) a perífrase entrou mais abruptamente no sistema (também no fim do século XIX), o verbo teve seu movimento reduzido para checar somente traços de modo. Desse modo, o sentido de futuro é capturado pelo traço IRREALIS.

Sob um ponto de vista da linguística formal, o processo de analiticização é, de certa forma, um fenômeno recentemente explorado. Assim, investigações mais profundas, por exemplo, a analiticização do tempo presente ('eu estou almoçando neste momento' vs. 'eu almoço neste momento'), precisam ser feitas a fim de estabelecer uma melhor compreensão sobre como o enfraquecimento temporal afetou a estrutura sintática do PB.

\section{Referência}

ABUSCH, Dorit. On the Temporal Composition of Infinitives. In: GUÉRON, Jacqueline \& LACARME, Jacqueline (eds.). The syntax of Time. Cambridge, MA: MIT Press, 2004. cap. 1. p. 27-53.

AMBAR, Manuela; GONZAGA, Manuela; NEGRÃO, Esmeralda. Tense, quantification and clause structure in EP and BP. Evidence from a comparative study on 'sempre'. In: BOK-BENNEMA, Reineke et al. (eds.). Current Issues in Linguistic Theory 256. Amsterdam, Philadelphia: John Benjamins, 2004. cap. 1. p. 1-16. 
ARAÚJO-ADRIANO, Paulo Ângelo. Alguns aspectos sobre a expressão do futuro no português brasileiro: fala, escrita e representação. Mosaico, São José do Rio Preto, v. 15, p. 493-523, 2016.

Sintaxe e diacronia da expressão de futuridade no PB. 2019a. 206 f. Dissertação (Mestrado em Linguística) - Instituto de Estudos da Linguagem, UNICAMP, Campinas. Como as crianças brasileiras adquirem a expressão de futuridade: um estudo sintático. Miguilim - Revista Eletrônica do Netlli. Crato. v. 8. n. 2. p. 708-727. maio/ago. 2019b.

A analiticização do tempo presente no PB do século XVIII: perífrase 'estar' + gerúndio vs. forma sintética. X Ciclo de Estudos da Linguagem e III Congresso Internacional de Estudos da Linguagem - CIEL. 29-31 jul. 2019. Universidade Estadual de Ponta Grossa Ponta Grossa 2019c. Não publicado.

. Conhecimento linguístico do letrado acerca das expressões de futuridade = forma perifrástica (gramática nuclear/L1) + forma sintética (gramática periférica/L2). (no prelo).

BERLINCK, Rosane de Andrade. A ordem V SN no portugues do Brasil: sincronia e diacronia. 1988. 265 f. Tese (Doutorado em Linguística) - Instituto de Estudos da Linguagem, UNICAMP, Campinas.

BIBERAUER, Theresa; ROBERTS, Ian. Subjects, tense and verb-movement. In: BIBERAUER, Theresa et al. (eds.). Parametric Variation: Null subjects in minimalist theory. Cambridge: Cambridge University Press, 2010. cap. 7. p. 263-302.

BRITO, Ana Maria. Clause structure, subject positions and verb movement about the positions of sempre in European Portuguese and Brazilian Portuguese. In: D’HULST,Yves; ROORYCK, Johan; SCHROTEN, Jan (eds.). Current Issues in Linguistic Theory 221. Amsterdam, Philadelphia: John Benjamins, 2001. cap. 3. p. 63-85.

CHOMSKY, Noam. Aspects of the Theory of Syntax. Cambridge, MA: MIT Press, 1965. . Lectures on Government and Binding: The Pisa Lectures. Dordrecht: Foris, 1981. . The Minimalist Program. Cambridge, MA: MIT Press, 1995. . Minimalist inquiries: the framework. In: MARTIN, Roger; MICHAELS, David; URIAGEREKA, Juan (eds.). Step by Step: Essays on Minimalist Syntax. Cambridge, MA: MIT Press, 2000. cap. 3. p. 89-155. 
Derivation by phase. In: KENSTOWICZ, Michael (ed.). Ken Hale: A Life in Language. Cambridge, MA: MIT Press, 2001. cap. 1. p. 1-52.

CINQUE, Guglielmo. Adverbs and Functional Heads: a cross-linguistic perspective. New York: Oxford University Press, 1999.

COMRIE, Bernard. Aspect. Cambridge: Cambridge University Press, 1976.

CYRINO, Sonia. Algumas questões sobre a elipse de VP e objeto nulo em PB e PE. In: GUEDES, Marymarcia; BERLINCK, Rosane De Andrade \& MURAKAWA, Clotilde (orgs.). Teoria e análise lingüísticas: novas trilhas. Araraquara: Laboratório Editorial FCL/UNESP,SP, Cultura Acadêmica, 2006. cap. 5. p. 53-79.

On Richness of Tense and Verb Movement in Brazilian Portuguese. In: CAMACHO-TABOADA, Victoria; et al. (eds.). Information Structure and Agreement. Amsterdã: John Benjamins, 2013. cap. 12. p. 297-317.

; LOPES, Ruth. Null objects are ellipsis in Brazilian Portuguese. The Linguistic Review. Berlin. v. 33. n. 4. p. 483-502. 2016.

; MATOS, Gabriela. VP ellipsis in European and Brazilian Portuguese: a comparative analysis. Journal of Portuguese Linguistics. Lisboa. v. 1. n. 2. p. 177-195. 2002. ; MATOS, Gabriela. Local licensers and recovering in VP ellipsis. Journal of Portuguese Linguistics. Lisboa. v. 4. n. 2. p. 79-112. 2005.

; MATOS, Gabriela. Elipse do VP e variação paramétrica. Cadernos de Estudos Linguísticos. Campinas. v. 42. n. 2. p. 195-206. 2007.

; MATOS, Gabriela. Null Objects and VP ellipsis in European and Brazilian Portuguese. In: WETZELS, W. L.; MENUZZI, S. \& COSTA, J. (eds.). The Handbook of Portuguese Linguistics. Nova Jersey: Wiley-Blackwell, 2016. cap. 16. p. 294-317.

DEGRAFF, Michel. Verb syntax in, and beyond, creolization. In: HAEGEMAN, Liliane (ed.). The new comparative syntax. Nova Iorque: Longman Linguistics Library, 1997. cap. 3. p. 64-94.

DUARTE, Maria Eugênia. A perda do principio "evite pronome" no portugues brasileiro. 1995. 151 f. Tese (Doutorado em Linguística) - Instituto de Estudos da Linguagem, UNICAMP, Campinas.

ELLIOTT, Jennifer. Reallis and irrealis. Forms and concepts of the grammaticalisation of reality. Linguistic Typology. Berlin. v. 4. n. 1. p. 55-90. 2000. 
GALVES, Charlotte Marie Chambelland. O Enfraquecimento da Concordância no Português Brasileiro. In: ROBERTS, Ian; KATO, Mary (orgs.). Português Brasileiro: uma viagem diacrônica. Campinas: Editora da UNICAMP, 1993. p. 387-403. Ensaios sobre as gramaticas do português. Campinas: Editora da UNICAMP, 2001.

GIORGI, Alessandra; PIANESI, Fabio. Tense and aspect: From semantics to morphosyntax. Nova Iorque: Oxford University Press, 1997.

HORNSTEIN, Norbert. As Time Goes By: Tense and Universal Grammar. Cambridge, MA: MIT Press, 1990.

JACKENDOFF, Ray. Gapping and related rules. Linguistic Inquiry. Cambridge, MA. v. 2. n. 1. p. 21-35. 1971.

JOHNSON, Kyle. What VP ellipsis can do, and what it can't, but not why. In: BALTIN, Mark \& COLLINS, Chris (eds.). The handbook of contemporary syntactic theory. Oxford: Blackwell, 2001. p. 439-479.

KATO, Mary. Aquisição e aprendizagem: de um saber inconsciente para um saber metalinguistico. In: GRIMM-CABRAL, Loni; MORAES, José (orgs.). Investigações a linguagem: ensaios em homenagem a Leonor Scliar-Cabral. Florianópolis: Mulher, 1999. p. 201-225.

. A gramática do letrado: questões para a teoria gramatical. In: MARQUES, Maria Aldina; et al. (orgs.). Ciências da linguagem: 30 anos de investigação e ensino. Braga: Centro de Estudos Humanísticos Universidade do Minho, 2005. p. 131-145.

A gramática nuclear e a língua-I do brasileiro. In: MARTINS, Marco Antonio (org.). Gramática e Ensino. Natal: EDUFRN, 2013. v. 1 (Coleção ciências da linguagem aplicadas ao ensino). cap. 6. p. 149-164.

; ROBERTS, Ian (Orgs.). Português brasileiro: uma viagem diacrônica. 2. ed. Campinas: Editora da UNICAMP, 1993.

; NEGRÃO, Esmeralda Vailati (eds.). Brazilian Portuguese and the Null Subject Parameter. Madri: Iberoamericana Vervuert, 2000.

KOENEMAN, Olaf; NEELEMAN, Ad. Predication, verb movement and the distribution of expletives. Lingua. Amsterdam. v. 111. n. 3. p. 189-233. mar. 2001. 
LOBATO, Lucia. Os verbos auxiliares em português contemporâneo: critérios de auxiliaridade. In: LOBATO, Lucia (orgs.). Análises Linguísticas. Petrópolis: Vozes, 1975. p. 27-91.

LONGO, Beatriz; CAMPOS, Odete. A auxiliaridade: perífrases de tempo e aspecto no português falado. In: ABAURRE, Maria Bernadete; RODRIGUES, Ângela (eds.). Gramática do Português Falado. Campinas: Editora da UNICAMP, 2002. v. 8. cap. 12. p. $445-477$.

LUNGUINHO, Marcus Vinícius. Dependências morfossintáticas: a relação verbo auxiliar-forma nominal. Revista de Estudos da Linguagem. Belo Horizonte. v. 14. n. 2. p. 457-489. jun./dez. 2006.

. Verbos auxiliares e a sintaxe dos domínios não finitos. 2011. 215 f. Tese (Doutorado em Linguística) - Faculdade de Filosofia, Letras e Ciências Humanas, Universidade de São Paulo, São Paulo.

MATOS, Gabriela; CYRINO, Sonia. Elipse de VP no Português Europeu e no Português Brasileiro. Revista da Abralin. Fortaleza. v. 26. p. 386-390. 2001.

OLIVEIRA, Josane Moreira. O futuro da língua portuguesa ontem e hoje: variação e mudança. 2006. 254 f. Tese (Doutorado em Língua Portuguesa) - Faculdade de Letras, Universidade Federal do Rio de Janeiro, Rio de Janeiro.

PESETSKY, David; TORREGO, Esther. The syntax of valuation and the interpretability of features. In: KARIMI, Simin; SAMIIAN, Vida; WILKINS, Wendy (eds.). Phrasal and Clausal Architecture: Syntactic Derivation and Interpretation. Amsterdã: John Benjamins, 2007. cap. 14. p. 262- 294.

POLLOCK, Jean- Yves. Verb Movement, Universal Grammar and the Structure of IP. Linguistic Inquiry. Cambridge, MA. v. 20. n. 3. p. 365-424. 1989.

RECH, Nubia. Auxiliaridade verbal uma análise dos núcleos funcionais ir e ter no português brasileiro. Cadernos do IL. Porto Alegre. n. 46. p. 65-89. jun. 2013.

REICHENBACH, Hans. Elements of Symbolic Logic. Nova Iorque: Macmillan \& Co, 1947. REINTGES, Chris; CYRINO, Sonia. Analyticization and the syntax of the synthetic residue: A macrocomparative perspective. In: MARTINS, Ana Maria; CARDOSO, Adriana (Orgs.). Word Order Change. 1. ed. Oxford: Oxford University Press, 2018. cap. 10. p. 179-201. 
RESENDE, Maurício; ARAÚJO-ADRIANO, Paulo Ângelo. Os verbos ir, dever e poder e seus infinitivos: sintaxe interna e externa. Revista de Estudos da Linguagem. Belo Horizonte. v. 27. n. 2: Formal Grammar Studies. p. 935-966. 2019.

ROBERTS, Ian. A formal account of grammaticalisation in the history of Romance futures. Folia Linguistica Historica. Berlin. v. 26. n. Historica. p. 219-258. 1992. . Verbs and diachronic syntax: a comparative history of English and French. Dordrecht: Kluwer, 1993.

; ROUSSOU, Anna. Syntactic change: a Minimalist approach to grammaticalization. Cambridge: Cambridge University Press, 2003.

ROSS, J. Constraints of variables in syntax. 1967. 501 f. Tese (Ph.D. em Linguística) Department of Linguistics and Phylosophy, Massachusetts Institute of Technology, Massachusetts.

. Guess Who?. In: BINNICK, Robert et al. (eds.). Papers from the sixth regional meeting of the Chicago Linguistics Society. Chicago: Departament of Linguistics, University of Chicago, 1969. p. 252-286.

TARALLO, Fernando. Relativization strategies in Brazilian Portuguese. 1983. 270 f. Tese (Ph.D. em Linguística) - Department of Linguistics, University of Pennsylvania, Philadelphia.

VENDLER, Zeno. Verbs and Times. The Philosophical Review. Durham. v. 66. n. 2. p. 143-16o. abr. 1967.

VIKNER, Sten. V-to-I movement and inflection for person in all sentences. In: HAEGEMAN, Liliane (ed.). The new comparative syntax. Nova Iorque: Longman Linguistics Library, 1997. cap. 8. p. 189-213.

WURMBRAND, Susi. Infinitives are tenseless. University of Pennsylvania Working Papers. Filadélfia. v. 13. n. 1. p. 407-420. 2007. . Tense and Aspect in English Infinitives. Linguistic Inquiry. Cambridge, MA. v. 45. n. 3. p. 404-447. 2014. 